\title{
Do differences exist between how Engineering and non-Engineering lecturers perceive the importance of teaching competences?
}

\author{
Antoni Perez-Poch \\ Institute of Education Sciences \\ Universitat Politècnica de Catalunya - BarcelonaTech \\ Barcelona, Spain \\ antoni.perez-poch@upc.edu
}

\author{
David López \\ Institute of Education Sciences \\ Universitat Politècnica de Catalunya - BarcelonaTech \\ Barcelona, Spain \\ david@ac.upc.edu
}

\begin{abstract}
A survey we conducted a few years ago concluded that higher education teachers should have the following competences: interpersonal, methodological, communicative, planning and management, teamwork and innovation. The authors of this work belong to the Institute in charge of the lecturer-training program at our university, which is basically a technical one. In order to improve our training program, we pose the following research questions: What are the competences that lecturers perceive as less important. Do our university teachers (engineering teachers) have a different perception of the importance of the different lecturer competences compared to that of other teachers? The results we present in this paper come from a survey that was sent to a total of 15,209 teachers belonging to public universities in our community, and we received a total of 2,347 valid answers. As a result of this study, we found which competences are those with a significantly bad rating by lecturers in general, and our lecturers in particular. We analyze what measures should be introduce into our teachertraining program.
\end{abstract}

Keywords- Lecturer competences; teachers perception; engineering education

\section{INTRODUCTION}

The pedagogical training of university lecturers has not been the result of a systematic and studied process, but rather a voluntary self-training based on seminars or training activities, personal readings, information sharing with peers, and, above all, on reflection derived from teaching experience.

Lecturers' opinions of their own work as teachers rely on the students attending their lectures, on the subject being taught, on previous experience and on their own beliefs, which make people work as if these beliefs were true [1]. These beliefs are relatively stable and resistant to change, as well as being consistent with the teaching style of each lecturer. It is difficult for lecturers to change their beliefs, particularly if they are intuitively reasonable [2]. For this change to occur, lecturers should feel some sense of dissatisfaction. In addition, they should be provided with an intelligible and clearly useful alternative. Finally, lecturers should find a way to connect these new beliefs with their previous ones [3].
Our University, the Universitat Politècnica de Catalunya BarcelonaTech (hereinafter UPC), only offers degrees in engineering, architecture and mathematics. We have neither schools nor departments of psychology or education. There is also no tradition in social science methods in our faculty. In such an environment, our lecturers do have the technical skills required for teaching, but not necessarily the professional skills required for a good teaching practice. This is particularly problematic in an environment of engineering studies, which traditionally has one of the highest dropout rates in Higher Education.

The authors of this article belong to the Institute for Education Sciences (hereafter referred to with the acronym ICE in our language). This Institute is responsible for offering teachers a lecturer-training framework. Such training is voluntary for lecturers, since there is no specific teacher training background required for teaching at the university, other than the knowledge related to the subject to be taught.

As ICE is in charge of the lecturer-training program of our university, we are accustomed to asking our teachers about their training needs, but we also conduct research into what a lecturer-training program must offer above and beyond our lecturers' beliefs. Lecturers' training in engineering has been studied in recent years $([4,5]$, to name but a few). These studies focus on the methods and tools required for a quality teaching practice. However, a paradigm shift in learning is taking place.

In the European Higher Education Area (EHEA), we are moving from content-based to skills-based learning $([6,7,8])$. Given this situation, we believe that the lecturers' training program should also be based on skills: such training should include skills such as communication capability, or planning and management of the syllabus.

To this end, a group of universities in Catalonia decided to start a joint project to define which skills a lecturer should possess [9]. This undertaking is described in the following section, but an important part of it consisted of a survey designed to detect the importance that teachers gave to each skill. When this data had been collected, we started the 
research work presented here, the final goal of which is to adapt our lecturer-training program to the real needs of our teachers.

\section{PURPOSE}

\section{A. Previous work: the GIFD competences study}

The Interuniversity Group of Teacher Training (GIFD from its acronym in our language) is a study group composed of professionals in charge of teacher training programs in the eight public universities of Catalonia, Spain. These universities account for 149,116 out of the 169,418 university students in Catalonia (88\%). This group carried out a study on the skills a university teacher should possess, the first step being a review of the literature on these skills, which was conducted in 2011.

The initial results were discussed in a focus group composed of 64 teachers in which all fields of knowledge were represented. From this study, and once the validation was concluded, six competences a university teacher should have were identified. We prefer to use the term "competence" instead of "skill". Although the term "skill" is often used interchangeably with "competence", the difference for us resides in the fact that, while skills are defined as the ability to apply knowledge and use know-how to complete tasks and solve problems, competencies are the proven ability to use knowledge, skills, and personal, social, and/or methodological abilities, both in work or study situations and in professional and personal development [10]. Thus, competence may be conceptualized as the duality of skills (knowledge) and experience [11].

The six competences identified are as follows:

- Interpersonal competence (IC): know-how to help students to develop critical thinking, motivation, confidence, and the recognition of diversity and individual needs. All this must be accomplished by creating a climate of empathy and ethical commitment that includes ethics in the professional practice as well as interaction with other individuals or groups.

- Methodological competence (MC): knowledge of the modern methods and strategies of teaching and learning, and awareness of different learning models. Teachers must encourage and enhance learning as well as the development of personal and professional skills through the application of appropriate methodological strategies and evaluation, in accordance with the educational context and situation.

- Communicative competence (CC): teachers should develop communication processes in an appropriate and efficient way, which means reception, performance, production and transmission of messages through various media channels and in a contextualized in teaching-learning situation. These channels include face-to-face interaction as well as written documents or new media such as videos, interactive tools and social media software.

- Planning and management competence (PMC): knowhow to design, guide and develop content, training and evaluation so that the results are measured and suggestions for improvement are made. Participation in interdisciplinary teams in a coordinated manner, in order to lead and / or assist in training and evaluation activities, generate new ideas and manage educational projects, with adaptation to new situations and needs, depending on the objectives and resources available.

- Teamwork competence (TC): this skill is not about teachers leading a group of students working together, but rather the ability of teachers to collaborate and participate as a member of a group. It is about taking on responsibilities and commitments according to the common objectives, agreed procedures and consideration of the available resources.

- Innovation competence (InnC): know-how to create and apply new knowledge, perspectives, methodologies and resources in the different dimensions of teaching. A critical approach to one's own beliefs and methods, search for new activities, and strategies or quality criteria all aimed at improving the quality of the teaching-learning process.

Each competence was then subdivided into several indicators, e.g. "promoting confidence" for the Interpersonal competence, or "using non-verbal language" for the Communicative one. A total of 49 such indicators were found for the six competences.

The list of indicators can be found below:

IC: Interpersonal Competence

IC1: Ethical commitment to training and profession.

IC2: Develop reflexive and critical thinking.

IC3: Inspire trust and confidence in negotiations with others.

IC4: Show tolerance toward other points of view and behavior that do not damage people or society.

IC5: Create a climate of empathy (empathy understood as putting oneself in someone else's shoes, understanding their point of view).

IC6: Identify individual needs.

IC7: Respect cultural diversity.

IC8: Promote self-confidence.

IC9: Encourage motivation.

MC: Methodological Competence.

MC1: Use methodological strategies that stimulate student participation.

MC2: Apply methodological strategies that promote a sense of student responsibility for their own learning and that of their classmates.

MC3: Ensure consistency between outcomes, teaching/learning methods and assessment processes. 
MC4: Design and develop teaching/learning activities and resources according to student characteristics, subject and learning context.

MC5: Apply different didactic strategies to improve communication between teachers and students and between students themselves.

MC6: Plan practical activities that encourage self-learning and the development of personal and professional skills.

MC7: Use new technologies critically and imaginatively to create learning situations and context that strengthen student autonomy.

MC8: Use new technologies selectively as support and medium for the development and improvement of the teaching/learning process.

MC9: Select and learn to use the new technologies belonging to one's own field of knowledge.

MC10: Use different formative assessment strategies.

MC11: Provide continuous feedback to stimulate student learning and autonomy.

\section{CC: Communication Competence}

$\mathrm{CC} 1$ : Structure discuss according to context, message and target audience.

CC2: Explain with clarity and enthusiasm.

CC3: Use definitions, examples and alternative explanations to facilitate understanding of the topic.

CC4: Identify communication barriers in the didactic context and plan strategies to facilitate good communication to students.

CC5: Create spaces where students can express freely their opinions about the subject, the teaching or the learning process; gather this information and provide response.

CC6: Express thoughts, feelings and emotions clearly and confidently in order to facilitate understanding of what one wishes to convey and show respect to others.

CC7: Regulate the voice, intonation, emphasis and breathing for clear verbal expression.

CC8: Use body language as appropriate.

CC9: Listen carefully to understand others' point of view.

\section{PMC: Planning and management Competence}

PMC1: Plan, manage and ensure teaching/learning processes according to established outcomes.

PMC2: Select and define syllabus in according with relevance to curriculum and professions.

PMC3: Plan and manage student training activities that facilitate learning and acquisition of competences.

PMC4: Design and manage assessment processes.

PMC5: Follow up tasks and use of resources to assess fulfillment of outcomes.

PMC6: Assess implementation of the program regarding learning and acquisition of competences; detect weaknesses and introduce improvement to ensure achievement of outcomes.

\section{TC: Teamwork Competence}

TC1: Direct, manage and/or coordinate teaching teams vertically and/or horizontally.

TC2: Delegate and /or distribute tasks according to levels of competence within the group.

TC3: Carry out tasks effectively in order to fulfill the outcomes established by the team.

TC4: Act for the good of the team.

TC5: Facilitate adaptation of the team in changing situations.

TC6: Follow up tasks and activities undertaken by the group and introduce the changes required to achieve outcomes.

TC7: Assess cost-benefit balance in the work conducted by the team.

\section{InnC: Innovation Competence}

InnC1: Analyze teaching/learning context to identify areas for improvement and apply innovative strategies and/or resources.

InnC2. Revise teaching/learning processes to seek new strategies for improving these processes.

InnC3. Define precisely the aim of the innovation to be undertaken.

InnC4. Adapt innovations to the characteristics and peculiarities of each context.

InnC5. Introduce innovations whose aim is to improve the teaching/learning process.

InnC6. Active participation in projects and experiences of educational innovation.

InnC7. Evaluate and transfer innovation results and experiences to the teaching/learning context for improvement of educational quality.

Finally, the results were endorsed by a survey among university teachers, in which they were asked about the importance they gave to each competence and indicator consisting of a total of 55 items (6 competences plus 49 indicators). Every item was marked using a Likert forced scale as "not important" (1); "somewhat important" (2); "important" (3); or "very important" (4). The poll was validated using the judges' method. This method consists of the selection of judges or experts who perform an analysis of a given developed instrument, and therefore expressing a quality judgement based on three indicators: uniqueness (the item may include more than one question), appropriateness (a true relationship exists between the objectives of the survey and the question in the item); and the importance of the overall survey. A total of 54 experts validated the survey, and as a result some items were modified or eliminated from it. The questionnaire was sent to all of the 15,209 teachers working in the eight universities, obtaining a total of 3,472 answers. For the current study, we have considered 2,347 (15.43\%) valid answers. Answers were considered as valid if the respondents had stated a value for 6 competences and for all 49 indicators. Incomplete answers where one or more lacking item valuations were discarded. 


\section{B. Our Research Questions}

On the basis of these results, we started a deep analysis of data in order to detect which items were considered of less importance, and to determine if there were any differences between our own teachers and the rest. We already knew that our teaching staff may have a different perception of their role as teachers from that of teachers from other non-technical universities, with faculties, colleges, departments and research groups specializing in pedagogy. With that aim in mind, we started to develop our own research study in which we analyzed which competences and skills were perceived differently from the other teaching staff. This study was of specific interest for us, since the ICE is the institute responsible for teaching training in our University [12]. We were therefore interested in determining what differences existed in our training program in order to take them into account; in particular, in order to promote those competences which are most poorly perceived as important by our teaching staff.

Our research questions are as follows:

1. What are the competences and indicators most poorly perceived by the university lecturers?

2. Are the perceptions from our technical university different than those from other non-technical universities? If these differences exist, are there any statistically significant differences?

Therefore, what conclusions may be drawn from these results regarding our lecturer-training program?

The work we present here is a research in which we use the results of the previously mentioned survey.

As stated in the previous section, the sample consists of 2,347 teachers from the eight public Catalan universities who answered the survey. The sample was answered by a total of $46 \%$ female and $54 \%$ male teachers, while the percentage of female lecturers in Catalan public universities was 36\%. The survey was not mandatory and the teaching staff was informed that their answers would be used anonymously only for research purposes.

From all valid answers received, 503 were from UPC teachers out of a total of 2,522 teachers employed at our University (19.9\%). In the original study, it was stated that the minimum sample size should be 390 teachers in order to achieve a maximum error of 5 percent. The sample finally obtained and analyzed far exceeds this requirement.

Statistical analysis was conducted with the statistical software IBM SPSS ${ }^{\mathrm{R}}$ for Windows, version 19 [13].

\section{RESULTS}

Regarding our research question "Are teaching perceptions different depending on the teachers belonging to UPC or to a non-technical public university in Catalonia", we conducted a t-student comparison between the answers' sample from UPC $(\mathrm{N}=503)$ or that from the other universities $(\mathrm{N}=1,844)$.
TABLE I. AVERAGE OF TEACHERS' PERCEPTION OF THE IMPORTANCE OF PROFESSIONAL COMPETENCES

\begin{tabular}{|l|c|c|}
\hline \multicolumn{1}{|c|}{ Competence } & NON-UPC & UPC \\
\hline Interpersonal (IC) & 3.52 & 3.46 \\
\hline Methodological (MC) & 3.52 & 3.43 \\
\hline Communicative (CC) & 3.62 & 3.58 \\
\hline Planning and management (PMC) & 3.46 & 3.42 \\
\hline Teamwork (TC) & 3.20 & 3.13 \\
\hline Innovation (InnC) & 3.27 & 3.19 \\
\hline
\end{tabular}

First of all, we provide the average of the teachers' perception of the six competences under investigation, (1-low importance, 5- very important) for teachers belonging to and not belonging to our technical university UPC. Significant differences are found for the Methodological competence $(\mathrm{t}=3.02, \mathrm{p}=0.003)$, Teamwork competence $(\mathrm{t}=2.00, \mathrm{p}=0.045)$ and Innovation competence $(\mathrm{t}=2.17, \mathrm{p}=0.030)$. All averages are inferior in the case of teachers from UPC. Results are given in Table I.

The information in Table I does not indicate which competences are the best and most poorly valuated. A more qualitative analysis of data was required, so we decided to analyze whether any studied item had been noted as having low importance by any of the two studied populations. To that end, we analyzed which items were perceived as less important, considering as low values those stated as a low or of no importance (answers 1 and 2) and high values as those stating quite important or very important (answers 3 and 4). A competence or item receiving more than $15 \%$ of low values is regarded as of low value (answers 1 and 2).

Table II shows these results for the two populations: teachers from UPC and teachers from the other universities. Each cell contains the percentage of answers with values 1 or 2 in the survey.

TABLE II. PERCENTAGE OF TEACHERS Who HAVE VALUED EACH COMPETENCE WITH LOW VALUES

\begin{tabular}{|l|c|c|}
\hline \multicolumn{1}{|c|}{ Competence } & NON-UPC & UPC \\
\hline Interpersonal (IC) & 3.98 & 1.13 \\
\hline Methodological (MC) & 3.87 & 1.78 \\
\hline Communicative (CC) & 2.39 & 0.34 \\
\hline Planning and management (PMC) & 5.45 & 3.04 \\
\hline Teamwork (TC) & 12.98 & 16.78 \\
\hline Innovation (InnC) & 10.82 & 12.45 \\
\hline
\end{tabular}


TABLE III. INDICATORS WITH LOW VALUES, PERCEIVED AS OF LITTLE IMPORTANCE (PERCENTAGE OF ANSWERS 1 OR 2 IN THE SURVEY).

\begin{tabular}{|c|c|c|}
\hline Item & NON-UPC & UPC \\
\hline IC7 & 15.99 & 15.73 \\
\hline MC4 & 12.13 & 15.04 \\
\hline MC5 & 14.21 & 15.11 \\
\hline MC7 & 24.38 & 25.38 \\
\hline MC8 & 17.75 & 16.23 \\
\hline MC9 & 15.42 & 13.98 \\
\hline MC10 & 20.10 & 19.25 \\
\hline MC11 & 15.43 & 16.44 \\
\hline $\mathrm{CC} 5$ & 17.76 & 16.42 \\
\hline CC6 & 17.50 & 19.26 \\
\hline $\mathrm{CC} 7$ & 16.93 & 16.28 \\
\hline $\mathrm{CC} 8$ & 19.78 & 22.30 \\
\hline $\mathrm{TC} 1$ & 16.84 & 18.25 \\
\hline $\mathrm{TC} 2$ & 17.1 & 19.20 \\
\hline TC4 & 14.79 & 16.44 \\
\hline TC5 & 16.01 & 17.02 \\
\hline TC6 & 15.23 & 18.25 \\
\hline TC7 & 24.68 & 31.12 \\
\hline InnC2 & 13.88 & 15.28 \\
\hline InnC3 & 18.82 & 22.12 \\
\hline InnC6 & 23.44 & 28.93 \\
\hline InnC7 & 17.04 & 20.34 \\
\hline
\end{tabular}

Table III is similar to Table II, but in this case we show one by one the indicators that belong to this competence. Each cell contains the percentage of answers with values ' 1 ' or ' 2 'in the survey. Those highlighted cells indicate those that exceed $15 \%$.

We assumed unequal variances checked this inequality with Levene's test [14]. These results are given in Table IV together with the significance of these differences. Finally, Table IV shows differences between the perceptions of individual items, for those items where significantly differences were found. It is important to point out that all the values expressed by UPC teachers are always lower on average than those expressed by the other public non-technical universities in Catalonia.
TABLE IV. DIFFERENCES BETWEEN ITEMS STATED BY TEACHERS FROM UPC AND THOSE FROM THE OTHER UNIVERSITIES.

\begin{tabular}{|l|c|c|c|}
\hline \multicolumn{1}{|c|}{ Item } & NON-UPC & UPC & p-value \\
\hline IC7 & 3.19 & 3.11 & $<0.05$ \\
\hline IC8 & 3.37 & 3.29 & $<0.05$ \\
\hline MC1 & 3.46 & 3.38 & $<0.05$ \\
\hline MC2 & 3.36 & 3.28 & $<0.05$ \\
\hline MC4 & 3.24 & 3.16 & $<0.05$ \\
\hline MC5 & 3.18 & 3.11 & $<0.05$ \\
\hline CC4* & 3.31 & 3.21 & $<0.01$ \\
\hline TC1 & 3.12 & 3.04 & $<0.05$ \\
\hline TC6 & 3.16 & 3.09 & $<0.05$ \\
\hline TC7 & 2.97 & 2.89 & $<0.05$ \\
\hline InnC7* & 3.56 & 3.04 & $<0.01$ \\
\hline
\end{tabular}

\section{DISCUSSION}

\section{A. The need for professional competences}

Much study has been devoted to the importance of including professional competences in engineering studies. According to Smerdon [15], the ABET engineering criteria [16] can be divided into two categories: hard and professional (soft) competences. These latter include communication, teamwork, understanding ethics and professionalism, engineering within a global and societal context, lifelong learning, and knowledge of contemporary issues. The rapid changes in contemporary society make the acquisition of professional competences more crucial every day, so in recent years how to teach and assess these competences have been the focus of several works (see for instance, the comprehensive review by Shuman et al [17]). Although we are speaking about the professional competences of engineers, most of these competences are common to all studies (like teamwork, communication and so).

Given the importance for our students to acquire these competences, the following question arises: do university lecturers possess these competences? More specifically, can we teach competences if we lack them ourselves, or do we as teachers simply give no importance to acquiring them?

A survey described in [18] on the attitudes of students, faculty and professionals in computing to teaching content and assessment shows that these groups share a set of professional values, although students are less convinced of their importance in the work environment. A broad consensus exists to the effect that explicit teaching and assessment of professional values and behaviors may encourage convergence between the academic and employment goals and environments, as well as creating better career prospects for 
more graduates. On the other hand, in their study, conducted in Kentucky, Hassan, Maharoff, and Abidn [19] report that recently graduated Engineers in current employment perceived that these competences are neglected in their curriculum. It is striking to discover that teachers responsible for Engineer training are those that assign less importance to the value of these competences in the curriculum. Watson [20] surveyed both students and teachers in engineering studies in Malaysian universities. In that author's survey, based on a sample of 488 students and 332 teachers, it was found that a significant relationship exists between the level of application of these competences and the teaching method used in class.

In the light of these studies, we consider that detection of which competences are considered of low importance by lecturers, as well as the assistance needed to help them appreciate and acquire such competences, are of great importance for the future opportunities of our students. This is therefore a mandatory objective when designing a lecturertraining program.

\section{B. Competences and indicators perceived as having low importance}

Table I shows that, on average, teachers consider the six competences as quite important, on the mean range between 3.20 and 3.62 in a scale from 1 to 4 (3.13 and 3.58 in the case of UPC lecturers). However, when we classify the answers into low importance and very important (Table II), we can see that four of the competences (Interpersonal, Methodological, Communicative and Planning and Management) are highly rated by all teachers, while Teamwork and Innovation are accorded less importance. It is necessary to point out that we are asking about the importance that teachers give to each competence for teachers and to be a good teacher, not for students and to be a good professional.

There are some points we wish to highlight for the analysis of the importance of the indicators (Table III):

- The most poorly rated competence is Teamwork; furthermore, all indicators of the competence (but one) are poorly rated. It appears that a significant number of lecturers consider that teaching is an individual activity rather than a team one.

- Innovation Competence is the second most poorly rated competence, especially the indicators InnC2, InnC3, InnC6 and InnC7. If we analyze what these indicators have in common, we observe that they propose activities outside the classroom (such as revising the learning-teaching process, defining the aim of the innovation, participating in innovation projects or transferring innovation results), while the indicators concerning activities in the classroom (analyzing context, adapting and introducing innovations in class) are more highly rated.

- None of the six indicators corresponding to the Planning and Management Competence have a low evaluation.
- Interpersonal Competence is one of the most highly rated, and only one indicator (ICT7) has a low evaluation. We believe that in this case one limitation is revealed in our study: this indicator is defined as "respect cultural diversity", and in Catalonia there exists a fairly homogeneous society. Thus, this indicator is perceived as being of less importance than in other more heterogeneous societies, such as the USA.

- The Methodological Competence yields some curious results: while it is one of the most highly rated competences, seven out of eleven elements have a low evaluation. The most highly rated elements are those in which the "traditional teacher role" is described: stimulation of student participation; promoting a sense of responsibility in the student; encourage self-learning, and ensuring consistency between outcomes and the assessment process. On the other hand, the most "innovative" parts are poorly rated: designing and developing activities adapted to all kind of students; using new technologies imaginatively; learning to use new tools; improving communication between teachers and students or between students themselves. It is important to point out that approximately $15 \%$ of teachers regard providing continuous feedback to stimulate student learning and autonomy as "not important" or "somewhat important", while this percentage rises to $20 \%$ when they are asked about using different formative assessment strategies.

- Similar results appear when we analyze the Communication Competence: this is the most highly rated Competence, although four out of nine elements are poorly rated. The worse ones include those concerning expression of thoughts, feelings and emotions by both teachers and students, and the use of clear verbal expression and appropriate body language by teachers.

These results leads us to conclude that, in our environment, university lecturers have not assimilated the EHEA principles. Most of the elements that are perceived as being of less importance are those that change the teacher-student "traditional" relationship, such as using new technologies to strengthen student autonomy (MC7), increasing formative assessment and feedback (MC10, MC11), and creating spaces where students can freely express their opinions about the subject, the teaching or the learning process (CC5). In addition, the fact that the Teamwork and Innovative competences are those perceived by most people as being less important shows that a group of traditional lecturers exist who are not concerned about introducing innovations into the classroom or about working in cooperation with their colleagues.

We also conclude that teachers regard the university as a "teaching process" rather than a "learning process". Our teachers give more importance to the scenarios in which they are the protagonists rather than those where the students have more responsibility and prominence. For instance, CC2 (explain with clarity and enthusiasm) is rated as being of great 
importance, while MC11 (provide continuous feedback to stimulate student learning and autonomy) receives a lower rating.

Finally, we wish to remark that, even if a competence receives a good rating, some of its indicators may be evaluated as being less important. It is our opinion that this problem is a question of definition. For instance, if teachers are asked about the importance of good communication, they state that it is a very important competence, but there are thinking about their own idea of communication, and it is necessary for them to understand that this competence encompasses much more than communication in one direction from teachers to students.

\section{Do engineering teachers have a different perception?}

As regards the second question about the existence of differences between the perception of the competences and indicators between lecturers belonging to our technical university or belonging to the other universities, we find some statistically significant differences in three competences and in eleven of the forty-nine indicators. In all cases, engineering lecturers are lower on average than lecturers from other universities.

The three competences accorded a significantly lower rating by our lecturers are Methodological, Teamwork and Innovation. This is perhaps surprising, because these three competences are fundamental for the research activity in which our lecturers are engaged. Engineering teachers appear to separate research from teaching activities [21], so three of the most highly regarded competences in the engineering (and research) world receive a significantly lower rating where teaching is concerned, despite the fact that teachers consider them to be highly important for the day-to-day work on engineering. We believe that this is due to the fact that their research methods are different from those used in social sciences, so it may be that our lecturers are unaware of the rigor in the methodologies, sampling and analysis of the samples behind a teaching innovation or the theories used in pedagogy.

From the indicators showing that UPC lecturers express significant differences, most of these differences concern the role of lecturers when helping students to acquire their own professional competences; for instance, MC5 (Apply different didactic strategies to improve communication between teachers and students and between students themselves.), IC8 (Promote self-confidence), and MC2 (Apply methodological strategies that promote a sense of student responsibility for their own learning and that of their classmates.). Other indicators are related with Teamwork, which is the competence receiving the lowest rating by all teachers and the one with more indicators showing a low value. In that case, engineering teachers are still more reluctant to consider these indicators as important. Finally, in the InnC7 (Evaluate and transfer innovation results and experiences to the teaching/learning context for improvement of educational quality) the difference is even greater $(p<0.01)$, which reinforces our conclusion that engineering teachers do not regard teaching innovation as being important.
These results indicate that an engineering lecturer-training program should be different from the training program of other universities in some regard: explaining social sciences research methods and insistence on the importance of applying innovation in education. In fact, we consider that the main issue is to emphasize the pedagogy of engineering as a field of research, and one which requires the same competences as any other research field: methodology, teamwork and innovation (among others). We agree with Patricia Cross who states that: "Teaching will not achieve a status until teachers consider their classes as laboratories for research and innovation" [22].

\section{Lessons learned}

We believe that all courses, workshops and seminars we organize will serve little purpose while teachers persist with their current convictions. As stated before, while there is still no organized and mandatory training program for lecturers, teachers will tend to approach teaching on the basis of their own experiences as students and in accordance with their current beliefs. It is now clear that our lecturer-training program must be strengthened, but as this program is still not mandatory, we are of the opinion that teachers whose beliefs remain unchanged will be reluctant to enroll. Changing these beliefs is not easy, but it requires above all a commitment from university and college management teams in order to motivate teachers to reconsider such beliefs.

Notwithstanding, any improvement in the training program must be founded on teaching lecturers about the importance of students' needs, as well as convincing them that it is not what they teach (and how they teach it) that is most important, but rather what students learn (and how they learn it). As Gardner and Willey indicate, "becoming a particular type of scholar or researcher and developing a higher level of expertise in a field of academic activity involves a transformation of identity" [23]. As a result of our study, we now know what factors must be strengthened and emphasized in order for teachers to increase their level of expertise in education and therefore convince them to change their minds, since some of our staff continue to regard education as a lecturer's task (teaching) rather than a student's task (learning).

Before concluding, we would like to point out that this study is subject to some limitations: it is restricted to state universities in Catalonia and the sample, however large, is neither random nor stratified. Nevertheless, we believe that the results can be extrapolated to other universities. As mentioned in the section on sample characteristics, the number of valid responses obtained is sufficiently large to be considered with a sampling error of less than 5\%. Finally, we wish to remark that we found no statistically significant differences in mean ratings when grouped according to teacher gender or age, although with respect to the current percentage of women lecturers belonging to the universities under study, the survey respondents consisted of a higher percentage of women than men. 


\section{CONCLUSIONS}

We present a study on teaching competences in higher education and the differences in perception expressed by teachers with regard to the importance of these competences. An analysis is performed to determine whether teachers from a technical university perceive these competences differently, when compared with the other universities in the same geographical area.

Detection of those items perceived as significantly more or less important provide us with indications to enable us to improve the design of the training program available to our teaching staff, as well as to focus our pedagogical approach on raising the awareness of these teachers about the real importance of such competences.

As future work, we intend to conduct further study on the reasons why some items are perceived as less important, and what possible actions may be taken to improve those perceptions.

\section{ACKNOWLEDGMENTS}

We wish to thank the other members of the GIFD group who have allowed us to use the results of the survey for our own research. We also wish to thank all the ICE team for their unconditional support.

\section{REFERENCES}

[1] M.D. Kagan. "Implication of research on teacher belief". Educational Psychologist, 27(1),65-90. 1992

[2] R.S. Prawat. "Teachers' beliefs about teaching and learning: A constructivist perspective". American Journal of Education. 100(3), pp 354-395. 1992.

[3] G.J. Posner, K.A. Strike, P.W. Henson, and W.A. Gertzog. "Accommodation of a Scientific conception: Toward a theory of conceptual change". Science Education Vol 66, 211-227, 1982.

[4] D. Fink, S. Ambrose, and D. Wheeler. "Becoming a Professional Engineering Educator: A New Role for a New Era". Journal of Engineering Education 94(1):185-198, 2005.

[5] J. Walther, N. W. Sochacka, and N. N. Kellam. "Quality in Interpretive Engineering Education Research: Reflections on an Example Study". Journal of Engineering Education, 102(4), 626-659, 2013.

[6] A. Mohan, D. Merle, C. Jackson, J. Lannin, and S. S. Nair. "Professional Skills in the Engineering Curriculum". Transactions on Education 53(4):562-571. November 2004.

[7] D. J. Moore, D. R. Voltmer, "Curriculum for an Engineering Reinaissance". IEEE Transactions on Education 46(4):452- 455. November 2003.
[8] H. J. Passow. "Which ABET Competencies Do Engineering Graduates Find Most Important in their Work?". Journal of Engineering Education, 101(1): 95-118. January 2012.

[9] I. Torra, I. del Corral, M.J. Pérez, X. Triadó, T. Pagès, E. Valderrama, M. D. Màrquez, S. Sabaté, P. Solà, C. Hernández, A. Sangrà, L. Guàrdia, M Estebanell, J. Patiño, A.-P. González, M. Fandos, N. Ruiz, M. C. Iglesias and A. Tena. "Identificación de competencias docentes que orienten el desarrollo de planes de formación dirigidos a profesorado universitario." REDU-Revista de Docencia Universitaria. 10(2):21-56. 2012

[10] European Parliament, European Council. "The European Qualifications Framework (EQF) for Livelong Learning". https://ec.europa.eu/ploteus/sites/eac-eqf/files/leaflet_en.pdf. Retrieved April 5, 2016.

[11] G. Bassellier, I. Benbasat, and B.H. Reich. "The Influence of Business Managers' IT Competence on Championing IT". Information Systems Research 14(4):317-336. 2003.

[12] D. López, A. Adam, M. J. Delgado, E. Mayol and M. Alier. "A design pattern for skills based lecturer training programs". Proceedings of the 6th Research in Engineering Education Symposium (REES 2015). Dublin, Ireland. July, 13-15 2015.

[13] IBM SPSS ${ }^{\mathrm{R}}$ Solutions for Education. Available on line: http://www-01.ibm.com/software/analytics/spss/academic/

[14] A. Field, "Discovering statistics using SPSS (and sex and drugs and rock 'n' roll)". London (2009). $3^{\text {rd }}$ Edition. SAGE ISBN 978-1-84787-906-6.

[15] E. Smerdon, "An Action Agenda for Engineering Curriculum Innovations" 11th IEEE-USA Biennial Careers Conference, Nov. 11 2003. http://www.ieeusa.org/careers /careercon/proceeding/ esmerdon.pdf Last access March 2011.

[16] ABET. Accreditation Criteria. Accreditation Board for Engineering and Technology, Inc. http://www.abet.org/. Last access, march 2011.

[17] L.J. Shuman, M. Besterfield-Sacre, and J. McGourty. "The ABET Professional Skills - Can They Be Taught? Can They Be Assessed?" Journal of Engineering Education, 94 (1), 41-55 (2005).

[18] U. Fuller, J.C. Little, B. Keim, C. Riedesel, D. Fitch and S- White, "Perspectives on developing and assessing professional values in computing", in SIGCSE Bulletin 41(4): 174-194 (2009).

[19] A. Hassan, M. Maharoff, and N. Zainal Abidn. "The Readiness of lecturers in embedding soft skills in the bachelor's degree program in Malaysian institutes of teacher education". Journal of Education and Training Studies. 2 (3) 2014.

[20] F. Watson "Self-Perceptions of Interpersonal, Intrapersonal, and Leadership Skills among Recent Engineering Graduates: A Qualitative Study". Phd Dissertation. University of the Rockies (2013). ISBN: 9781-3032-9827-1.

[21] J. Miró Julià, D. López, and R. Alberich. "Education and Research: Evidence of a Dual Life". In Proceedings of the 8th International Computing Education Research Workshop (ICER 2012), pp 17-22. Auckland, New Zealand, September 10-12, 2012.

[22] K. Patricia Cross. "A proposal to improve teaching". AAHE Bulletin, 39(1):9-15, September 1986.

[23] A. Gardner, and K. Willey. "Engineering Academics' Identity Transactions in Becoming Established Engineering Academic Researchers". Proceedings of the $6^{\text {th }}$ Research in Engineering Education Symposium (REES 2015). Dublin, Ireland, 13-15 July 2015. 